\title{
Adaptation at the interface of forest ecosystem goods and services and livestock production systems in Northern Mali
}

\author{
Maria Brockhaus \& Houria Djoudi
}

\section{Key points}

- Spontaneous or autonomous reactive adaptation in response to climate change can be observed in the ecological and human subsystems around forests and local ecosystem services.

- Adaptation in the socio-political subsystem is entirely lacking or lagging behind, and this is hindering the switch from spontaneous to planned adaptation through reflective and strategic decisionmaking processes.

- Local adaptation needs development interventions that take into account existing strategies, to avoid maladaptive action or even action nullifying local adaptation efforts.

- Coordination needs to improve across all levels, sectors, and actors in public and private spheres, to support sustainable adaptation processes in the socialecological system.

- Local adaptation needs adaptive governance at all levels to support a planned approach and to meet the criteria for sustainable natural resource management.
Adaptation to climate change is a need and a challenge for ecosystems, for human beings, and for governance systems at all levels. In West Africa, livelihoods depend heavily on forest ecosystem goods and services, often in interplay with agricultural and livestock production systems. Technical and societal adaptation is needed to reduce the growing risk of vulnerability under climate change.

National policies and programs as well as development interventions need to be designed so that adaptation is not hindered but enabled. Revised governance structures may support adaptation at multiple levels and layers (Brockhaus \& Kambire, 2009). Local institutions in particular play a key role (Agrawal 2008). However, gaps are often observed between local adaptation realities and the global and national processes. Even though local adaptation frequently occurs autonomously and spontaneously, adaptation and the importance of forest ecosystem goods and services have not yet been sufficiently mainstreamed into governance structures, policies, regulations, and development projects and programs (Locatelli et al. 2008). Consequently, local adaptation to climate change for sustainable natural resource management lacks an appropriate political and institutional framework, or can even be counteracted by interventions that do not take account of existing local adaptive responses. Further efforts are needed to link local efforts to national and global approaches, and ensure planned and strategic adaptation to climate change.

This is confirmed by preliminary results from a comparative study on adaptation at the interface 
between forests and mobile and sedentary livestock production systems. The study was conducted in the Tombouctou region, district of Goundam, in the northern part of Lake Faguibine, Mali. It was undertaken by the EU-financed research project TroFCCA (Tropical Forests and Climate Change Adaptation) from July to October 2008.

The study was designed as demand-oriented research combining national and local activities. In order to feed research results immediately into on-going adaptation processes, the site selection was based on an initial interview phase at national level to harmonise research activities with national processes. This was followed by further interviews at regional level (Tombouctou) and a workshop on vulnerability and adaptation to climate change at district level (Goundam). An intense field research was then undertaken at two sites north of the Lake Faguibine area (Tin Aicha and Raz'al'Ma), combining bio-physical (transects: forest cover, density, estimation of biomass production, etc.) and participatory social research related to livestock production systems, natural resource utilization and adaptation strategies. To capture various perspectives and preferences in line with other vulnerability studies in Mali, workshops were carried out with three different groups: adult men, women and young people.

The last research phase was aimed at informing national and international stakeholders in Mali on local adaptation responses. Here, science could act as a bridge and broker between local realities and national interests.

\section{The ecological sub-system}

In the past, the Lake Faguibine was a priority area for agriculture and fishery, but the Niger River-fed water system dried out with the droughts of the 1970s and 80 s. Although the region has a long history of rainfall variability, the trend in recent decades has been consistent with climate change scenarios, with lower rainfall and more frequent, more severe droughts. This trend has contributed to Lake Faguibine drying out completely (Salomon et al. 1987). Various development interventions have taken place since then, are ongoing or planned for the near future with the aim, among other objectives, of restoring the traditional waterbased economic activities (for example Ministère de l'Agriculture 2005; http://www.unep.org/pdf/LakeFaguibine.pdf).

However, the Lake Faguibine ecosystem has changed drastically and a transition from a water-based to a forest ecosystem has taken place. Indeed, more than a third of the lake area has naturally reforested with Acacia sp. and Prosopis sp. (which was introduced in the 1980s as a measure against desertification and to protect the lake edges). The highly invasive Prosopis sp. has reforested areas at a faster rate than local species such as Acacia sp. on the north-western side.

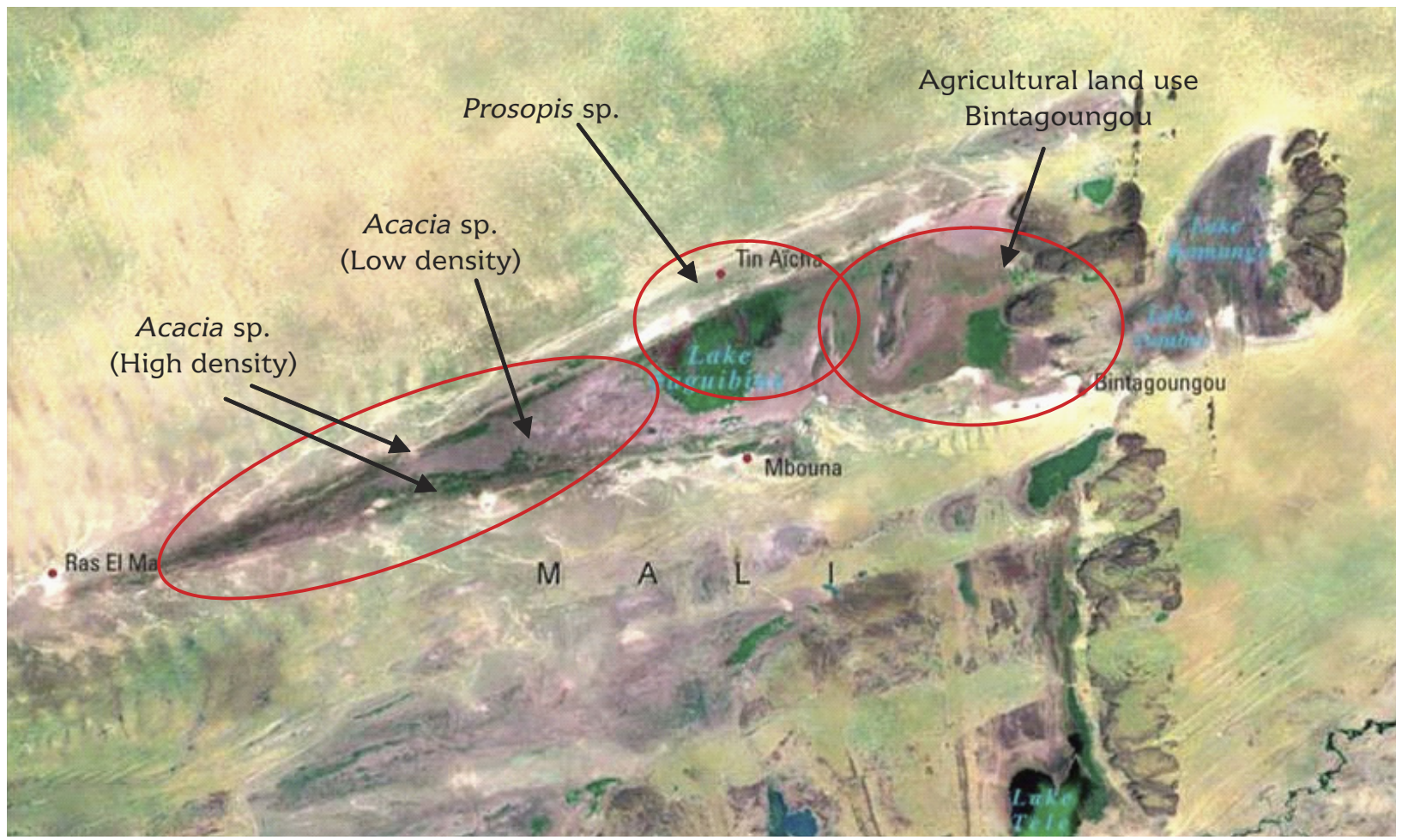

Source: NASA October 2006, with author additions 
Climate-related changes are one driver for the lake's ecosystem transformation, but other factors have also contributed to this natural reforestation. They include the lake area's high soil fertility and the strong reduction in animal pressure during the rebellion in the 1990s. The research results suggest that the area's ecological sub-system has undergone an autonomous adaptation, enabled by a plurality of factors. However, full use of potential forest ecosystem goods and services from Prosopis and Acacia, such as fodder and charcoal, would need an enhanced forest management system.

\section{The human sub-system}

The social sub-system is undergoing adaptive changes to exploit forest resources. Agricultural and fisherybased systems are being transformed into agro-sylvopastoral, and the pastoral systems to sylvo-pastoral. The forests play an extremely important role in the livestock systems, especially as a safety net in dry years.

However, there is a strong distortion between the perceived value of the forest and the de-facto use of its ecosystem goods and services. This can be explained by psychological barriers due to the massive change and 'traumatisms' attached to the ecosystem's transformation; these may hinder acceptance of the change, followed by strategic and planned adaptation. The wish for a 'return of the lake' is also nurtured by promises from various parties over the past three decades.

Younger people in the villages often regard migration strategies as a necessary but not preferred way of adaptation; many express concern about instability and losing social networks if they leave their communities. Given a choice, they would rather stay home. Migration patterns can be differentiated as reactive adaptation with 'no-return', or as strategic adaptation to support the remaining population/family through external income or knowledge transfer by: a) settling outside the supported system and transferring capital or, b) accumulating capital outside and investing by returning to the community. Women have adapted to the new forest ecosystem by identifying new income-generating activities such as charcoal. However, market access will be the key to their success. Other responses are related to the livestock systems, where herd diversification is a major trend along with changing patterns of mobility including combining partially sedentary and partially mobile herds.

The research results show that the human or social sub-system is adapting to climate change in a spontaneous or autonomous way, but long-term resource management planning and therewith a strategic adaptation for the use of the ecosystem goods and services under climate change was not observed.

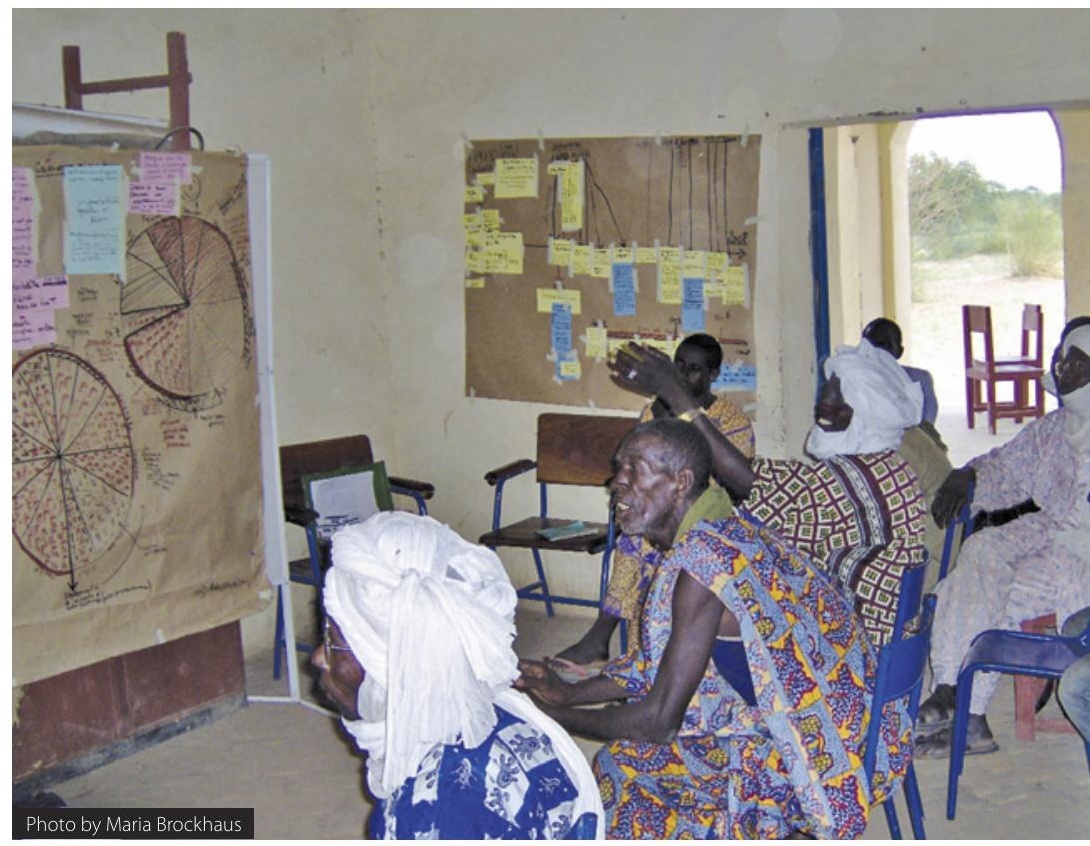

Adults meeting in Tin Aicha (historical axe and fodder calendar as participatory tools)

\section{The socio-political sub-system}

Despite the observed local adaptation efforts, these processes are not accompanied by adequate institutional and political change and so remain isolated and spontaneous. Even in a decentralization context, institutional and political support for local adaptation could not be observed:

(1) No management plans or other local institutions to sustainably manage the forest resources could be identified.

(2) No technical or capacity support by governmental bodies to manage the forest could be identified (knowledge, forest infrastructure investments, and so forth).

(3) No efforts by development or government agencies to valorize the forest ecosystem goods and services (markets, access) could be identified.

(4) No adaptive legislative framework exists (land not used for agriculture becomes state property after 10 years).

(5) The ongoing decentralization process has not transferred rights and resources for forest ecosystem goods and services until now.

The local population seems to be entirely disconnected from higher-scale planning and decision-making processes, especially higher-level adaptation activities. Adaptation to the new situation (which has actually existed for more than 30 years) could not be observed in the socio-political subsystem. 


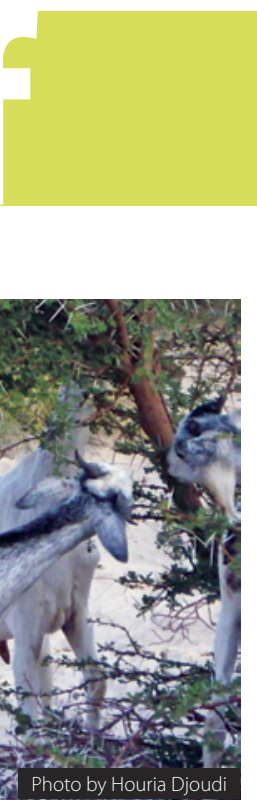

Forests providing fodder resources

However, spontaneous or autonomous local adaptive responses will not be sufficient to fulfill criteria for long-term sustainable natural resource management. To ensure sustainable adaptation, the institutional and political governance structure across all levels needs to show willingness and flexibility to ensure strategic and planned adaptation from the local to the global level. Such processes could be supported by improving horizontal and vertical coordination of adaptation and development activities. Further investments are needed in capacity building, and technical, financial, and scientific resources, to support the adaptation already taking place at the interface of livestock production systems and forests, in the Lake Faguibine area, and elsewhere.

Development interventions need to further mainstream adaptation to climate change in the planning and implementation processes, so as to avoid disturbing local adaptation efforts and instead support these spontaneous adaptation processes.

Ongoing efforts for more sustainable long-term development should be supported over realizing shortterm economic or political gains.

\section{References}

Agrawal, A. (2008). The Role of Local Institutions in Adaptation to Climate Change. International Forestry Research and Institutions Program (IFRI) Working Paper \# W081-3, University of Michigan.

Brockhaus, M. and Kambire, H. (2009). Decentralization - Window of Opportunity for Successful Adaptation? In: Adapting to climate change: thresholds, values, governance (eds.) Adger, N.W., Lorenzoni, l. and O’Brien, K., Cambridge University Press, Cambridge (forthcoming).

Bouard, S. and Tiers, S. (2004). Le lac Faguibine, un espace agropastoral au nord Mali: dynamiques agraires, gestion des ressources naturelles et stratégies des acteurs. Mémoire ESAT2-DIAT, option AGIR., CNEARC, Montpellier.

Locatelli, B., Kanninen, M., Brockhaus M., Colfer C.J.P., Murdiyarso, D. and Santoso, H. (2008). Facing an Uncertain Future: How forests and people can adapt to climate change. CIFOR Forest Perspectives, Bogor, Indonesia (in press).

Ministère de l'Agriculture (2005). Etude de faisabilité du projet d'aménagement et de mise en valeur du système Faguibine. Groupement Hydropacte/ Sadiconsult, Bamako.

Solomon, S.I., Beran, M. and Hogg, W. (1987). The Influence of Climate Change and Climatic Variability on the Hydrologic Regime and Water Resources, IAHS Pub. No. 168, IAHS Press, Wallingford.

UNEP (draft). http://www.unep.org/pdf/LakeFaguibine.pdf (as seen 06.11.08).

\section{Acknowledgements}

This document has been produced with the financial assistance of the European Union. The contents are the sole responsibility of the authors and under no circumstances should be regarded as reflecting the position of the European Union.

For further information, please contact:

Maria Brockhaus m.brockhaus@cgiar.org

Houria Djoudi djoudihou@gmail.com

\section{http://www.cifor.cgiar.org/trofcca/}

For general inquiries contact cifor@cgiar.org

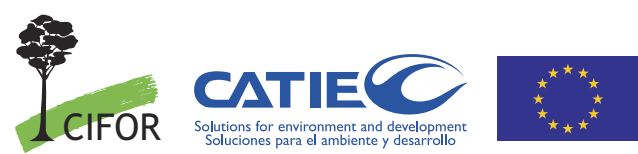

Center for International Forestry Research (CIFOR) advances human well-being, environmental conservation, and equity by conducting research to inform policies and practices that affect forests in developing countries. CIFOR is one of 15 centres within the Consultative Group on International Agricultural Research (CGIAR). CIFOR's headquarters are in Bogor, Indonesia. It also has offices in Asia, Africa and South America. CIFOR works in over 30 countries worldwide and has links with researchers in 50 international, regional and national organisations. www.cifor.cgiar.org 